\title{
Can headache impair intellectual abilities in children? An observational study
}

This article was published in the following Dove Press journal:

Neuropsychiatric Disease and Treatment

31 October 2012

Number of times this article has been viewed

\author{
Maria Esposito' \\ Antonio Pascotto' \\ Beatrice Gallai ${ }^{3}$ \\ Lucia Parisi ${ }^{2}$ \\ Michele Roccella ${ }^{2}$ \\ Rosa Marotta ${ }^{4}$ \\ Serena Marianna Lavano ${ }^{4}$ \\ Antonella Gritti ${ }^{5}$ \\ Giovanni Mazzotta ${ }^{6}$ \\ Marco Carotenuto' \\ 'Center for Childhood Headache, \\ Clinic of Child and Adolescent \\ Neuropsychiatry, Second \\ University of Naples, Naples, ${ }^{2}$ Child \\ Neuropsychiatry, Department \\ of Psychology, University of \\ Palermo, Palermo, ${ }^{3}$ Unit of Child \\ and Adolescent Neuropsychiatry, \\ University of Perugia, Perugia, \\ ${ }^{4}$ Department of Psychiatry, "Magna \\ Graecia" University of Catanzaro, \\ Catanzaro, ${ }^{5}$ Suor Orsola Benincasa \\ University, Napoli, 'Unit of Child and \\ Adolescent Neuropsychiatry, Azienda \\ Sanitaria Locale 4, Terni, Italy
}

Correspondence: Maria Esposito

Center for Childhood Headache, Clinic of

Child and Adolescent Neuropsychiatry,

Second University of Naples, Via Sergio

Pansini 5 PAD XI, 80I3I Naples, Italy

$\mathrm{Tel}+398 \quad 15666988$

Fax +398 I566 6694

Email mariaesp1980@libero.it
Background: The purpose of this study was to assess the cognitive functioning of children affected by headache, pinpointing the differences in intelligence style between subjects affected by migraine without aura and subjects with tension-type headache.

Methods: The study population consisted of 147 children (mean age $10.82 \pm 2.17$ years) with headache, recruited from the Headache Center for Developmental Age, Child and Adolescent Neuropsychiatry Clinic, Second University of Naples. Cognitive profiling was performed using Weschler Intelligence Scale for Children Third Edition throughout the sample. According to the International Classification of Headache Disorders II criteria for pediatric age, subjects were divided into a migraine without aura group ( $\mathrm{n}=75 ; 43$ boys, 32 girls $)$ and a tension-type headache group ( $n=72 ; 49$ boys, 23 girls). The results were compared with the findings obtained from a sample of 137 healthy control subjects recruited from schools in the Campania region, matched for age and gender.

Results: No difference in full intelligence quotient was found between the groups, but the children with tension-type headache had a lower verbal intelligence quotient and a higher performance intelligence quotient than the healthy controls and children with migraine. Factor analysis data showed that the children with migraine seemed to have lower perceptual organization than the children affected by tension-type headache.

Conclusion: To our knowledge, studies on cognitive functioning in children affected by headache in the interictal phase are scarce, and our results suggest a new perspective in understanding of the neuropsychological aspects of young patients affected by headaches.

Keywords: childhood headache, intelligence quotient, Weschler Intelligence Scale for Children Third Edition, intelligence, migraine

\section{Introduction}

Primary headaches are probably the most frequent and painful neurological symptom in childhood, with a prevalence of $2 \%-17 \%$ for migraine without aura and $0.9 \%-24 \%$ for tension-type headache, ${ }^{1}$ and a high disabling grade. ${ }^{2}$ The impact of primary headache on cognitive functioning is not yet well understood or considered in clinical practice. However, knowledge of the relationship between cognitive styles and functioning could help to clarify the pathogenesis of headache, given that a significant correlation has been reported between analytic cognitive style and cluster headache in adults, ${ }^{3}$ although the prevalence of cluster headache in childhood could be considered scarce according to a recent systematic review. ${ }^{4}$ Conversely, reports dealing with the neuropsychological performance of patients affected by migraine during the interictal period are relatively scarce and tend to show discrepant findings. 
Some authors have suggested that subjects affected by migraine may experience transient deficits in cognitive functions, ${ }^{5-11}$ without a specific link and/or a specific relationship between migraine symptoms, their duration and intensity, and the cognitive impairment. ${ }^{12-15}$ Alternatively, other reports have shown that memory, ${ }^{5,8,10,11}$ speed of information processing, ${ }^{5}$ attention, ${ }^{8,10,11}$ and psychomotor ability ${ }^{8,9}$ seem to be the most frequent neuropsychological functions which are altered in patients affected by headache, even if not present in all subjects.

A recent report has suggested a higher prevalence of developmental coordination disorder and borderline motor skills in children affected by migraine, ${ }^{16}$ that could be related to their cognitive performance, particularly the reduction in perceptual organization abilities found in children suffering from migraine without aura. ${ }^{17}$ On the other hand, the presence of headache in late adulthood could seem to be related to worse performance on some measures of executive functioning, suggesting that a cognitive impact is not specific to migraine but might be associated with headache in general. ${ }^{18}$ Anyway, few studies have been published concerning the impact of primary headaches on cognitive performance in childhood. ${ }^{19-21}$ Therefore, the aim of this study was to assess the cognitive profiles of children affected by headache, highlighting the differences in intelligence style between children suffering from migraine without aura and those with tension-type headache.

\section{Materials and methods Population}

Data were collected from a pilot group (10 migraine without aura, 10 tension-type headache, and 10 control children) and used to perform the sample size calculation. The desired power was set at 0.80 and error at 0.05 . The sample size was calculated using online software (http://www.dssresearch. com/toolkit/sscalc/size_a2.asp). The sample size required was found to be 24 subjects, ie, eight for each group, but there was the opportunity to recruit more patients (147 in total) in order to strengthen our findings. Therefore, the study population consisted of 147 children with headache (mean age 10.82 \pm 2.17 years) recruited from the Headache Center for Developmental Age, Child and Adolescent Neuropsychiatry Clinic, Second University of Naples.

Exclusion criteria were mental retardation (intelligent quotient [IQ] <75), association of different types of headache, previous prophylactic therapy for migraine, changes in neuroradiological (magnetic resonance imaging or computed tomography scan), neurophysiological (wake and sleep electroencephalogram), or blood chemistry results, concomitant neurological (epilepsy, movement disorders, cerebral palsy) or psychiatric disorders (schizophrenia, mood and anxiety disorders, psychosis, eating disorders, attention deficit hyperactivity disorder), metabolic disease, thyroid disease, obesity, and sleep-related breathing disorders. Cognitive profiling was performed for all three groups. Using the International Classification of Headache Disorders (IHCD) II criteria for the pediatric age group, ${ }^{22}$ the sample was divided into a group of children affected by migraine without aura ( $\mathrm{n}=75 ; 43$ boys, 32 girls) and a group of children with tension-type headache ( $\mathrm{n}=72 ; 49$ boys, 23 girls).

Following recruitment, there was a 4-month run-in period to verify headache characteristics. The minimum length of headache (for both types) required for admission in this study was 8 months, with a minimum of eight attacks monthly, each lasting for a duration of one hour, according to ICHD-II criteria. Subjects in both groups were recruited from the same urban area, and were all of Caucasian origin and of middle socioeconomic status. All parents gave their written informed consent. The results were compared with the findings obtained in a sample of 137 healthy controls (93 boys, 44 girls; mean age $10.78 \pm 2.35$ years) recruited from schools in the Campania region, who were matched for age $(P=0.882)$ and gender $(P=0.417)$. The departmental university ethics committee of the Second University of Naples approved the study (protocol number 178/2011), which was conducted according to the criteria of the Declaration of Helsinki. ${ }^{23}$

\section{Cognitive evaluation}

The Italian version of the Wechsler Intelligence Scale for Children Third Edition (WISC-III) ${ }^{24}$ for subjects aged 6-16 years was administered to all the children. Specifically, the WISC-III is composed of 13 distinct subtests divided into two scales, ie, a verbal scale and a performance scale. The six verbal scale tests use language-based items, whereas the seven performance scales use visual-motor items that are less dependent on language. Five of the subtests in each scale produce scale-specific verbal and performance IQs, and the 10 subtest scores produce a full scale IQ. Moreover, this test allows further evaluation of the characteristics of intelligence according to four factors that describe intelligence abilities by study of the subtests, ie, verbal, comprehension, and perceptual organization factor scores provide further statistically derived measures of language-related, visual-perceptual integration, and visual-motor skills, with freedom from distractibility and processing speed. 
The WISC-III is one of the most widely used measures of intelligence, ${ }^{25}$ and it has been assumed that its scores cannot be interpreted ambiguously, ${ }^{26}$ because the scale can measure the same construct(s) from person to person..$^{24}$ Initial analyses of the WISC-III standardization sample found that it was best represented by a four-factor, first-order structure, whereby verbal comprehension is composed of information, similarities, vocabulary, and comprehension subtests; perceptual organization is composed of picture completion, picture arrangement, block design, and object assembly subtests; freedom from distractibility is composed of arithmetic and digit span subtests; and processing speed is composed of coding and symbol search subtests. ${ }^{24}$ In general, the reported four-factor structure of the WISC-III normative sample has been accepted, but with some disagreement surrounding the smaller freedom from distractibility and processing speed factors. ${ }^{27,28}$ For this reason, only verbal comprehension and perceptual organization factors and differences in verbal comprehension-perceptual organization were taken into account in our study. Also, the difference between verbal IQ and performance IQ was used, as indicated in the validation criteria.

\section{Statistical analysis}

Mean differences in IQ scores, factor analysis, and anthropometric and clinical characteristics between the migraine without aura, tension-type headache, and control groups were analyzed by $t$-test. The Chi-square test was applied to evaluate the gender distribution in the three groups. Bonferroni correction was applied. A $P$ value $<0.01$ was considered to be statistically significant. Commercially available Statistica software (StatSoft Inc, Tulsa, OK) was used for the statistical evaluation.

\section{Results}

The mean ( \pm standard deviation) frequency of headache was $10.128 \pm 2.842$ attacks per month, the mean number of months with headache was $12.346 \pm 2.019$, and the mean duration of headache was $4.914 \pm 2.275$ hours. The headache group (147 subjects) was composed of 75 children with migraine without aura and 72 children with tension-type headache matched for age $(P=0.38)$ and gender $(P=0.241)$ and the headache group (migraine without aura and tensiontype headache) was matched with the control group (Table 1). Table 2 shows no difference in full IQ between the three groups, but a lower verbal IQ and a higher performance IQ in the tension-type headache group compared with the healthy controls and migraine without aura group. Factor analysis data show that the children with migraine tended to have lower perceptual organization competence than the healthy controls or the children with tension-type headache.

\section{Discussion}

Despite the considerable advances in knowledge about the pathophysiological features of headache, the exact effects of migraine on daily life are still not entirely understood, particularly with regard to developmental age. To our knowledge, studies reporting cognitive functioning in the interictal phase for children affected by headache remain scarce and have produced conflicting results. Therefore, our results could suggest a new perspective in understanding the neuropsychological aspects of young patients affected by headaches.

The first relevant study performed by D'Andrea et al in 1989 was in a sample of 20 children affected by migraine without aura (aged 7-11 years) and failed to identify any particular deficits in cognitive functioning, except for significantly impaired performance on short-term and long-term memory tasks. ${ }^{19}$ Moreover, in 2002, Haverkamp et al reported no significant differences on a scale assessing sequential and simultaneous information processing in children aged 6-12 years with migraine or in their healthy siblings. ${ }^{20}$ In this regard, our findings suggest that the cognitive functioning of children with headache may be considered to be different from that in healthy children.

In an Italian cross-sectional study in 2010, Parisi et $\mathrm{al}^{21}$ suggested that the verbal skills of school-aged children with

Table I Anthropometric and clinical characteristics among children with migraine without aura, tension-type headache, and controls

\begin{tabular}{|c|c|c|c|c|c|c|}
\hline & \multirow{2}{*}{$\begin{array}{l}\text { MoA } \\
(n=75)\end{array}$} & \multirow{2}{*}{$\begin{array}{l}\text { TTH } \\
(n=72)\end{array}$} & \multirow{2}{*}{$\begin{array}{l}\text { Control } \\
(n=137)\end{array}$} & \multicolumn{3}{|l|}{$\boldsymbol{P}$} \\
\hline & & & & $\begin{array}{l}\text { MoA versus } \\
\text { control }\end{array}$ & $\begin{array}{l}\text { TTH versus } \\
\text { control }\end{array}$ & $\begin{array}{l}\text { MoA versus } \\
\text { TTH }\end{array}$ \\
\hline Age & $10.66 \pm 2.65$ & $10.97 \pm 1.52$ & $10.78 \pm 2.35$ & 0.731 & 0.526 & 0.38 \\
\hline Gender distribution (M/F) & $43 / 32$ & $49 / 23$ & $93 / 44$ & 0.167 & 0.896 & 0.241 \\
\hline Z-score BMI & $0.56 \pm 0.24$ & $0.59 \pm 0.39$ & $0.51 \pm 0.25$ & 0.159 & 0.073 & 0.52 \\
\hline Frequency of attacks & $11.78 \pm 6.53$ & $12.9 \pm 5.23$ & - & - & - & 0.254 \\
\hline
\end{tabular}

Abbreviations: BMI, body mass index; MoA, migraine without aura; TTH, tension-type headache. 
Table 2 Mean and standard deviation for cognitive indices in children with migraine without aura or tension-type headache, and control children

\begin{tabular}{|c|c|c|c|c|c|c|}
\hline & \multirow{2}{*}{$\begin{array}{l}\text { MoA } \\
(n=75)\end{array}$} & \multirow{2}{*}{$\begin{array}{l}\text { TTH } \\
(n=72)\end{array}$} & \multirow{2}{*}{$\begin{array}{l}\text { Control } \\
(n=137)\end{array}$} & \multicolumn{3}{|l|}{$P^{a}$} \\
\hline & & & & $\begin{array}{l}\text { MoA versus } \\
\text { normal }\end{array}$ & $\begin{array}{l}\text { TTH versus } \\
\text { normal }\end{array}$ & $\begin{array}{l}\text { MoA versus } \\
\text { TTH }\end{array}$ \\
\hline VIQ & $102.65 \pm 15.44$ & $98.58 \pm 10.51$ & $105.31 \pm 13.44$ & 1.35 & 0.002 & 0.453 \\
\hline PIQ & $92.73 \pm|4.5|$ & $101.42 \pm 14.28$ & $95.02 \pm 13.58$ & 1.775 & 0.012 & 0.002 \\
\hline FIQ & $97.31 \pm 16.39$ & $99.63 \pm 11.80$ & $100.23 \pm 12.49$ & 1.027 & 5.134 & 2.293 \\
\hline VC & $104.76 \pm 18.74$ & $99.12 \pm 9.80$ & $103 \pm 13.12$ & 2.979 & 0.198 & 0.171 \\
\hline PO & $91.42 \pm 13.95$ & $99.47 \pm 13.58$ & $96.6 \pm 11.99$ & 0.035 & 0.829 & 0.003 \\
\hline VC-PO & $13.34 \pm 16.56$ & $-0.34 \pm 14.25$ & $6.4 \pm 12.52$ & 0.005 & 0.003 & 0.000 \\
\hline VIQ-PIQ & $9.92 \pm 8.38$ & $-2.83 \pm 14.17$ & $10.4 \pm 15.88$ & 5.65 & 0.000 & 0.000 \\
\hline
\end{tabular}

Note: ${ }^{B}$ Bonferroni-corrected value.

Abbreviations: MoA, migraine without aura; VIQ, verbal intelligent quotient; PIQ, performance intelligent quotient; FIQ, full intelligent quotient; TTH, tension-type headache; VC, verbal comprehension; PO, perceptual organization.

headache could be considered less developed than for those without headache, with no differences between children with migraine and those with tension-type headache. In contrast, our results suggest that the intelligence profile of the two headache groups (migraine without aura and tensiontype headache) is quite different, with children suffering from tension-type headache showing a slight reduction in verbal ability (even if not significant) and an increasing in the perceptual organization respect of chldren affected by migraine without aura.

Moreover, in 2008, Schmitz et al showed a correlation between impaired executive function in adult migraineurs and a deficit in density of the frontal and parietal gray matter, suggesting that abnormalities in the fronto-striatalparietal network are strongly associated with this specific interictal impairment. ${ }^{29}$ Impairment of executive function and abnormalities in frontal lobe structure may explain also the decreased perceptual organizational ability seen in our children with migraine without aura. In addition, we should consider the role that psychological factors and/or personality traits may play in neuropsychological performance, considering that anxiety levels tend to be higher in children with migraine than in controls. ${ }^{19}$

Some limitations of this study need to be taken into account, in that subjects were recruited from a specific region in Southern Italy and assessment of intellectual functioning was limited. Notwithstanding these limitations, our study does identify differences in intellectual ability in children affected by headache and suggests the need for a new academic approach to such children, ie, enhancing verbal activity for those with migraine without aura and using a logic-deductive approach for those affected by tension-type headache.

\section{Disclosure}

The authors report no conflicts of interest in this work.

\section{References}

1. Kernick D, Campbell J. Measuring the impact of headache in children: a critical review of the literature. Cephalalgia. 2009;29:3-16.

2. Mazzotta G, Gallai B, Mattioni A, et al. Cost assessment of headache in childhood and adolescence: preliminary data. J Headache Pain. 2005;6: 281-283.

3. Buonfiglio M, Di Sabato F. Analytic cognitive style in cluster headache. Neurol Sci. 2011;32:875-881.

4. Arruda MA, Albuquerque RC, Bigal ME. Uncommon headache syndromes in the pediatric population. Curr Pain Headache Rep. 2011;15: 280-288.

5. Zeitlin C, Oddy M. Cognitive impairment in patients with severe migraine. Br J Clin Psychol. 1984;23:27-35.

6. Hooker WD, Raskin NH. Neuropsychologic alterations in classic and common migraine. Arch Neurol. 1986;43:709-712.

7. Ardila A, Sanchez E. Neuropsychologic symptoms in the migraine syndrome. Cephalalgia. 1988;8:67-70.

8. Ai Q. A neuropsychologic study in migraine patients. Zhonghua Shen Jing Jing Shen Ke Za Zhi. 1992;25:92-95. Chinese.

9. Scherer P, Bauer H, Baum K. Alternate finger tapping test in patients with migraine. Acta Neurol Scand. 1997;96:392-396.

10. Le Pira F, Zappala G, Giuffrida S, Lo Bartolo ML, Morana R, Lanaia F. Memory disturbances in migraine with and without aura: a strategy problem? Cephalalgia. 2000;20:475-478.

11. Calandre EP, Bembibre J, Arnedo ML, Becera D. Cognitive disturbances and regional cerebral blood flow abnormalities in migraine patients: their relationship with the clinical manifestations of the illness. Cephalalgia. 2002;22:291-302.

12. Sinforiani E, Farina S, Mancuso A, Manzoni CG, Bono G, Mazzocchi A. Analysis of higher nervous functions in migraine and cluster headache. Funct Neurol. 1987;2:69-77.

13. Leijdekkers MLA, Passchier J, Goudswaard P, Menges LJ, Orlebeke JF. Migraine patients cognitively impaired? Headache. 1990;30:352-358.

14. Mulder EJCM, Linssen WHJP, Passchier J, Goudswaard P. Interictal and postictal cognitive changes in migraine. Cephalalgia. 1999;19: 557-565.

15. Bell BD, Primeau M, Sweet JJ, Lofland KR. Neuropsychological functioning in migraine in headache, nonheadache chronic pain, and mild traumatic brain injury patients. Arch Clin Neuropsychol. 1999;14:389-399. 
16. Esposito M, Verrotti A, Gimigliano F, et al. Motor coordination impairment and migraine in children: a new comorbidity? Eur J Pediatr. 2012 Jun 7. DOI:10.1007/s00431-012-1759-8.

17. Moutran AR, Villa TR, Diaz LA, et al. Migraine and cognition in children: a controlled study. Arq Neuropsiquiatr. 2011;69:192-195.

18. Martins IP, Gil-Gouveia R, Silva C, Maruta C, Oliveira AG. Migraine, headaches, and cognition. Headache. 2012 Jul 25. Doi:10.1111/j.15264610.2012.02218.x.

19. D’Andrea G, Nertempi P, Ferro Milone F, Joseph R, Cananzi JR. Personality and memory in childhood migraine. Cephalalgia. 1989;9:25-28.

20. Haverkamp F, Honscheid A, Muller-Sinik K. Cognitive development in children with migraine and their unaffected siblings. Headache. 2002;42:776-779.

21. Parisi P, Verrotti A, Paolino MC, et al. Headache and cognitive profile in children: a cross-sectional controlled study. J Headache Pain. 2010;11:45-51.

22. Headache Classification Subcommittee of the International Headache Society. The International Classification of Headache Disorders, 2nd ed. Cephalalgia. 2004;24 Suppl 1:9-160.
23. Declaration of Helsinki. BMJ. 1991;302:1194.

24. Wechsler D. Wechsler Intelligence Scale for Children, 3rd ed. San Antonio, TX: The Psychological Corporation; 1991.

25. Stinnett TA, Havey JM, Oehler-Stinnett J. Current test usage by practicing school psychologists: a national survey. J Psychoeduc Assess. 1994; 12:331-350.

26. Hoyle RH. Confirmatory factor analysis. In: Tinsley HEA, Brown SD, editors. Handbook of Applied Multivariate Statistics and Mathematical Modeling. New York, NY: Academic Press; 2000.

27. Grice JW, Krohn EJ, Logerquist S. Cross-validation of the WISC-III factor structure in two samples of children with learning disabilities. J Psychoeduc Assess. 1999;17:236-248.

28. Kush JC, Watkins MW, Ward TJ, Ward SB, Canivez GL, Worrall FC. Construct validity of the WISC-III for white and black students from the WISC-III standardization sample and for black students referred for psychological evaluation. School Psych Rev. 2001;30:170-188.

29. Schmitz N, Arkink EB, Mulder M, et al. Frontal lobe structure and executive function in migraine patients. Neurosci Lett. 2008; 440:92-96.
Neuropsychiatric Disease and Treatment

\section{Publish your work in this journal}

Neuropsychiatric Disease and Treatment is an international, peerreviewed journal of clinical therapeutics and pharmacology focusing on concise rapid reporting of clinical or pre-clinical studies on a range of neuropsychiatric and neurological disorders. This journal is indexed on PubMed Central, the 'PsycINFO' database and CAS.

\section{Dovepress}

The manuscript management system is completely online and includes a very quick and fair peer-review system, which is all easy to use. Visit http://www.dovepress.com/testimonials.php to read real quotes from published authors. 